\title{
Comunicação entre deputados federais brasileiros e cidadãos: há responsividade no contato por e-mail?
}

\author{
Luíza Amália Soares Franklin \\ Universidade Federal de Viçosa (UFV), Viçosa - MG, Brasil \\ Marco Aurélio Ferreira Marques \\ Universidade Federal de Viçosa (UFV), Viçosa - MG, Brasil

\section{Ana Paula Teixeira Campos} \\ Universidade Federal de Viçosa (UFV), Viçosa - MG, Brasil
}

Este trabalho buscou investigar o grau de responsividade dos deputados federais brasileiros quando contatados, por um cidadão, por meio eletrônico. Considerando as oportunidades de interação possibilitadas pelas tecnologias da comunicação e informação (TICs) e o dever da administração pública de um Estado democrático de dialogar com a população, verificou-se a importância de avaliar como os representantes do povo têm respondido ao contato realizado por um cidadão. Para tanto, foram realizados dois experimentos que consistiram no envio de e-mails para deputados federais, e as respostas foram analisadas com base em critérios advindos do conceito de "responsividade" princípio chave da democracia. Foram enviados três e-mails para cada parlamentar, mas o índice de resposta foi de apenas $11,16 \%$, número muito inferior ao obtido em outros estudos que aplicaram metodologia semelhante. No quesito qualidade das respostas, obteve-se notas regulares. Dessa forma, levando-se em conta o objeto de pesquisa aqui tratado, ou seja, os e-mails oficiais das deputadas e deputados, conclui-se que os parlamentares e seus assessores ainda apresentam um grande déficit quanto ao cumprimento do papel de informar e dialogar com os cidadãos. Assim, o uso de recursos tecnológicos oficiais na intermediação da relação entre parlamentares e população parece muito longe de atingir um caráter efetivamente democrático.

Palavras-chave: responsividade, tecnologia da informação e comunicação, Poder Legislativo, democracia 


\section{Comunicación entre diputados federales brasileños y ciudadanos: ¿hay responsividad en el contacto por correo electrónico?}

Este trabajo buscó investigar el grado de responsividad de los diputados federales brasileños cuando contactados por un ciudadano por medio electrónico. Reflexionando acerca de las oportunidades de interacción posibilitadas por las tecnologías de la información y comunicación (TICS) y el deber de la administración pública de un Estado democrático de dialogar con su pueblo, se verificó la importancia de evaluar como los representantes del pueblo han contestado el contacto hecho por un ciudadano. Para tanto, fueron realizados dos experimentos que consistieron en el envío de correos electrónicos para diputados federales, y las respuestas se analizaron en conformidad con criterios derivados del concepto de "responsividad" - principio clave de la democracia. Se enviaron tres correos electrónicos para cada político, pero el índice de respuesta fue solamente $11,16 \%$, número mucho más pequeño que el obtenido en otros estudios que emplearon metodología similar. En términos de calidad de las respuestas, se obtuvo puntuaciones regulares. Luego, poniéndose en cuenta el objeto de la investigación (los mensajes oficiales de diputadas y diputados), se concluye que los representantes y sus asesores todavía presentan un gran déficit en lo que respecta al cumplimiento de su papel de informar y dialogar con los ciudadanos. Así, el uso de los recursos tecnológicos gubernamentales en la intermediación entre parlamentares y pueblo parece estar muy lejos de alcanzar un efectivo carácter democrático.

Palabras clave: responsividad, tecnologías de la información y comunicación, Poder Legislativo

\section{Communication between Brazilian Federal Deputies and citizens: is there responsiveness in the contact by email?}

This paper sought to investigate the level of responsiveness of Brazilian federal deputies when contacted by a citizen through electronic media. Considering the opportunities of interaction made available by the information technology and communication (ICT) and taking into account the State public administration's duty to dialogue with its people; the importance of assessing how the government has been answering to a citizen was emphasized. To achieve so, two experiments, which consist in sending emails to Federal Deputies and analyzing their answers in the light of the responsiveness' concept (key principle of democracy), were conducted. Therefore, each representative received three emails, but the level of answers was only $11.16 \%$. This number was much inferior compared to other studies which applied a likewise methodology. As to the quality of the answers, they were ordinary; consequently, considering this research object (the official emails from deputies), it was concluded that the politicians and their advisors still present a big debt in terms of fulfilling their roles of informing and dialogue with the people. Hence, the use of governmental technological resources as intermediary between congressional and people seems very far from achieving democratic effectiveness.

Keywords: responsiveness, information and communication technology, Legislative Power 


\section{Introdução}

Diversas ferramentas digitais vêm sendo utilizadas nos estados democráticos ao redor do mundo, principalmente para aproximar o governo dos cidadãos. Ferramentas digitais de cunho institucional e pessoal vêm sendo adotadas para empoderar o cidadão (que passa a ter meios econômicos e práticos de se manifestar) e também para otimizar a gestão pública e resgatar a legitimidade do poder público (CUNHA; SANTOS, 2005; DADER, 2003; GOMES, 2005). Vale destacar que o e-mail é compreendido como o meio de comunicação oficial mais prático, econômico e acessível desde o início da adoção de ferramentas digitais, tanto para a administração pública (BRASIL, 2002) quanto para o povo (CUnha; SANTOS, 2005; DAder, 2003).

Ainda sobre esse cenário, Okot-Uma (2000) e Dias (2012) explicam que a sociedade contemporânea passou por mudanças de postura, passando de passiva para participativa, modificando consideravelmente a atitude dos atores envolvidos, a dinâmica do processo democrático e a forma de administrar os bens públicos. Esse novo contexto requer a adaptação do poder público e o monitoramento do cidadão, para que a comunicação entre os atores aconteça de forma democrática e responsiva.

Responsividade é, de modo geral, o ato de conhecer e - quando possível - atender às demandas da sociedade, sendo essa a chave da democracia, por ser a base da relação entre o serviço público e a população civil. Mais especificamente, Grohs, Adam e Knill (2015) explicam que esse princípio não se baseia apenas no ato de responder a um contato, mas sim de fazê-lo no tempo adequado, de forma completa e possibilitando um contato democrático, ou seja, aberto para o debate e focado no bem comum.

Seguindo essa perspectiva, o Legislativo aparece como o Poder que mais precisa agir responsivamente, pois se configura como a instituição central da democracia por ser responsável por receber e processar as demandas do povo (NogUEIRA, 2012). Esse requisito se mostra ainda mais importante na Câmara dos Deputados, pois ela recebe as demandas sociais diretamente (diferente do Senado, que analisa projetos previamente discutidos). Ainda assim, os deputados federais são historicamente mais distantes da 
sociedade do que os representantes das casas legislativas municipais e estaduais, devido a questões geográficas e culturais (CRUZ, et al., 2012; GAULD et al., 2016).

É fundamental, então, para a democracia, que a opinião pública seja ouvida e considerada pelo Poder Legislativo, o que torna o tema uma importante agenda de pesquisa. Dessa forma, muito se tem investigado sobre as ações democráticas de governos ao redor do mundo e seus resultados para a sociedade, especificamente sobre o uso da internet por legisladores brasileiros (Andersen; Medaglia; VATRAPU; HenRIKSEN; GaUld, 2011; BragA; Nicolás, 2009; BragA; Mitozo; TAdRA, 2016; Cruz, 2011; Nicolás; OliveirA, 2015; West, 2003; RICKEN; BRAgA, 2011).

Diante do que foi exposto, buscou-se investigar o grau de responsividade dos deputados federais brasileiros quando contatados por um cidadão por meio eletrônico. Para tanto, foi realizado um experimento que consistiu no envio de e-mails para deputados federais, e as respostas foram analisadas com base em critérios advindos do conceito de "responsividade".

É válido destacar que a todos os deputados federais é dada a mesma condição de atendimento ao público, uma vez que possuem e-mails institucionais hospedados e divulgados pela própria Câmara (a estrutura do e-mail é nomedodeputado@camara.leg. br) e que cada um deles possui uma verba de gabinete mensal de $\mathrm{R} \$ \mathbf{9 7 . 1 1 6 , 1 3}$ (valor estabelecido pelo Ato da Mesa 117/2016) para contratação de pessoal para atuar em funções diversas, tais como interação com o povo. Além disso, eles dispõem de vários documentos que os orientam com questões pontuais como redação, formato dos textos e estilo de escrita. Tudo isso permite supor que não há impedimento para que seja dada ao cidadão uma resposta de qualidade.

A seção a seguir discorre sobre responsividade, seguida pelo terceiro capítulo em que foi apresentada a metodologia da pesquisa -, depois pelos resultados, pelas considerações finais e, por fim, pelas referências bibliográficas. 


\title{
2 Responsividade no setor público
}

\begin{abstract}
"Responsividade" é um conceito criado no meio empresarial e importado para o âmbito estatal no surgimento do New Public Management (NPM), nos Estados Unidos, em resposta à crise fiscal dos anos 1970. Esse modelo é marcado por implementar princípios de negócios na entrega de serviços públicos, a fim de minimizar a insatisfação da população diante de uma onda de políticas públicas que não foram bem aceitas na Europa e nos Estados Unidos (DENHARDT, 2015; VIGODA, 2000).
\end{abstract}

Esse modelo foi importado pelo Brasil cerca de vinte anos depois - conhecido aqui como "administração pública gerencial" - em condições diferentes das originais e não foi bem adequado ao contexto brasileiro (DENHARDT, 2015).

Apesar de ter sido implementada em um modelo de gestão pública, a responsividade é um conceito chave para a democracia. Beetham (2006, p. 3, tradução nossa) trata de democracia como sendo "um ideal e um conjunto de instituições e práticas". Para elucidar o primeiro ponto de vista, o autor lista dois princípios: (1) o poder que todos os membros de uma associação qualquer possuem de participar e influenciar nas deliberações e tomadas de decisão do grupo e, assim, (2) todos seriam tratados igualitariamente. Tais questões se aplicam a qualquer grupo que associe indivíduos que comunguem qualquer tipo de interesse ou causa. A segunda perspectiva depende da primeira para se efetivar, pois é a partir de um ideal democrático que se formam as instituições e se desenvolvem práticas que concretizam esse sistema onde ele é adotado.

Dentre os regimes democráticos, há a democracia representativa, a qual vivemos hoje. Pitkin (1967, p. 16), em sua obra The concept of representation, explica que:

a representação é, em grande medida, um fenômeno cultural e político, um fenômeno humano". Esse fenômeno pode se concretizar "por meio das eleições [...], e após as eleições, quando os políticos tornam efetivas suas propostas manifestas no período eleitoral por meio da formulação e implementação de leis e políticas públicas" (MOREIRA, 2017, p. 22). 
Para que uma democracia representativa seja efetiva, Pitkin (1967) defende duas dimensões essenciais: accountability e responsividade. Ferejohn (1999) apresenta estes conceitos da seguinte forma: accountability está relacionada a estruturas das instituições democráticas, visando à prestação de contas e à externalização das razões que motivaram decisões tomadas pelos representantes; enquanto a responsividade aparece como uma consequência da interação dessas estruturas. Ele sintetiza as definições com a analogia que segue: "responsividade é a medida do quanto de accountability uma estrutura institucional permite" (FEREJOHN, 1999, p. 131, tradução nossa).

Apesar de defender a importância da accountability e da responsividade, Pitkin (1967) destaca que esse assunto é nebuloso porque não está claro como os representantes devem executar a ideia de representar o povo. Ela ainda ressalta que "está implícito que o governo deve, então, agir em benefício das pessoas, mas está igualmente implícito que isso não requer consulta nem responsividade para com seus desejos" (PITKIN, 1967, p. 130, tradução nossa). Entretanto, ao final de suas reflexões, a autora acredita que a representatividade requer responsividade perante o povo para atingir, de fato, seu propósito democrático.

Com o passar do tempo, estudiosos analisaram a ideia de responsividade e entenderam que ela pode ser compreendida, no setor público, de duas formas (VIGODA, 2002, p. 528): a primeira remete ao dever de atender ao cidadão como se ele fosse um cliente, o que levaria a uma distorção da finalidade pública, pois abriria a possibilidade de que questões "populistas" e de "curto-prazo" passassem à frente de outras de maior impacto e a longo prazo, entre outros aspectos.

Já a segunda maneira se refere a um modelo democrático aplicado à gestão pública "que exige administradores que sejam responsivos à vontade popular", mas não coniventes cegamente com as demandas, visão essa que requer um "setor público flexível, sensível e dinâmico" (VIGODA, 2002, p. 528). Adotou-se, para este trabalho, a segunda perspectiva, pois ela atende adequadamente o conceito de democracia aqui apresentado. Além disso, acredita-se que abrir espaço para o povo se manifestar e debater ações governamentais consiste em uma forma de legitimar a tomada de decisão e melhorar o desempenho da máquina pública. 
Para o alcance do objetivo proposto neste artigo, observou-se esse conceito de responsividade na comunicação direta estabelecida entre Poder Legislativo e cidadão. Essa escolha se deu porque este poder "é a expressão personificada do Estado Democrático Brasileiro" (RIBEIRO, 2012, p. 7). Legislar é, em suma, criar normas que regulam o funcionamento da sociedade; logo, os legisladores são políticos eleitos para exercer funções que visam a atender às necessidades do povo, o que pode acontecer de forma mais efetiva se houver comunicação entre esses atores. Enquanto o Poder Executivo gerencia e aplica o que o Legislativo entender que é melhor para a população, o Judiciário julga as ações e faz cumprir as leis (BACHTOLD, 2008).

Além disso, os parlamentares possuem outras funções, que vão além de legislar. São elas: representativa, legislativa, fiscalizadora, julgadora, político-parlamentar, orientação política, comunicativa, informativa e educativa (RIBEIRO, 2012). Diante de todas essas funções e de seu cunho democrático, infere-se que o Poder Legislativo possui o dever democrático de estabelecer uma "comunicação responsiva" com seus representados, ou seja, uma comunicação baseada na celeridade, no diálogo e na prestação de informações completas e claras. Esse tipo de contato almeja à construção de uma relação democrática entre os atores.

Sendo assim, espera-se que o contato estabelecido vá além de uma conversa comum, pelo contrário, ele precisa ser um momento de aprendizagem para o cidadão, que estará exercendo sua cidadania.

\section{Procedimentos metodológicos}

Para capturar o comportamento mais natural possível dos legisladores, optouse por realizar uma pesquisa experimental, que se configura em submeter grupos com características semelhantes a tratamentos diferentes e observar suas reações, verificando se os mesmos apresentam reações diferentes (2002). Esse tipo de pesquisa é comumente utilizado na observação de problemas complexos em que respostas naturais e espontâneas precisam ser captadas para verificar variáveis que influenciam tais respostas (GERHARDT; SILVEIRA, 2009). 
Tratando-se de estudos experimentais que investigaram "responsividade", Grohs, Adam e Knill (2015, p. 155, tradução nossa) relatam que "experimentos de campo fornecem uma ferramenta útil para testar a responsividade e o comportamento discriminatório de repartições públicas e podem ser aplicados em uma grande variedade de atividades e questões de pesquisa".

O e-mail foi o instrumento utilizado nos experimentos aqui analisados para averiguar a responsividade da Câmara dos Deputados. A opção por esse meio de comunicação justificase pelo fato de o correio eletrônico ser regimentado pela Casa. O Código de Ética e Decoro Parlamentar (2015), no Capítulo II - Dos Deveres Fundamentais, dos Atos Incompatíveis e do Atos Atentatórios ao Decoro Parlamentar - traz as obrigações fundamentais, tais como proteção da democracia e das instituições, tratamento igualitário a todos os atores democráticos, prestação de contas e busca pelo interesse público (BRASIL, 2015).

Quanto à regulação da comunicação direta entre cidadão e legislador, não há um mecanismo que o faça, tampouco foi criado um documento legal que regule a responsividade nesse contato. Existe, porém, a Portaria nㅇ 96, de 2004, que rege sobre o uso do "Serviço de Correio Eletrônico da Câmara dos Deputados", que tem como uma de suas funções a de ser um canal de interação entre sociedade e deputados federais, constatando a legitimidade desse canal e a obrigação dos parlamentares em responder. Além disso, para ter acesso a essa conta institucional, os legisladores assinam um termo de aceite, compromisso e responsabilidade, acusando ciência e aceitando as condições de utilização do e-mail. Esta pesquisa vem, nesse sentido, verificar como ocorre esse contato na ausência de um instrumento de fiscalização e controle, diante apenas do conhecimento de suas obrigações como parlamentares.

Há de se destacar que há outras formas de comunicação entre esses atores. Redes sociais como Twitter, Facebook e Instagram são exemplos de meios amplamente utilizados por governantes. Contudo, não é obrigatório que estes atores possuam essas ferramentas, o que tornaria inviável o diagnóstico sobre responsividade, almejado por esta pesquisa.

Os estudos anteriores enviaram mensagens para departamentos oficiais ou gabinetes de políticos com perguntas simples e - apesar das diferenças entre os métodos de análise - averiguaram de modo geral apenas se houve resposta, o tempo de retorno e 
se o conteúdo traz as informações requeridas, ou seja, pouco se observou em termos de qualidade da resposta e de efetividade da comunicação estabelecida.

Quatro categorias foram criadas para avaliar os e-mails: (a) uma se constituiu das melhores respostas por conterem respostas para ambas as perguntas e informações adicionais; (b) as que continham apenas o que foi perguntado; (c) aquelas com apenas uma das informações requeridas; e (d) as incompletas. Esses critérios foram utilizados posteriormente no artigo comparativo de Andersen et al. (2011) desenvolvido na Dinamarca. Os índices dos grupos C e D, contudo, foram altos em três países: 53,4\% das instituições neozelandesas, 37,1\% nas dinamarquesas e 69,3\% das australianas. Ao replicar esse experimento, Gauld et al. (2016) verificaram que as respostas se concentraram, mais uma vez, entre os grupos C e D, revelando que a qualidade da resposta não tem relação com a familiaridade dos servidores com a internet, uma vez que os próprios pesquisadores apontaram o fato de que no ano de 2015 - quando foi conduzida a pesquisa - o correio eletrônico já era um meio de comunicação popularizado nas instituições públicas.

Por fim, Grohs, Adam e Knill (2015b) adicionaram mais pontos de avaliação à sua investigação para verificar se havia tratamento diferente por parte dos governos locais alemães de acordo com o gênero e a nacionalidade do cidadão (neste caso, ele poderia ser turco ou alemão). Esses pesquisadores criaram, para tanto, três categorias que guiaram sua avaliação: "velocidade, completude e orientação para o serviço". A primeira dimensão se refere ao tempo de resposta; já a segunda está relacionada ao conteúdo e a apresentação da mensagem; e a terceira, por sua vez, constitui-se de critérios como profundidade da resposta, cordialidade e informações adicionais. Essas dimensões foram usadas como base para o desenvolvimento deste artigo e estão desmembradas na seção metodológica a seguir.

\subsection{Coleta de dados}

Para contatar os 513 deputados federais com mandatos vigentes no período corrente, foi acessado o canal "Quem são", dentro do menu "Deputados", do site da Câmara. Por esse meio, é possível fazer o download de uma planilha atualizada com os contatos de todos os deputados em exercício, como endereço do gabinete em Brasília, telefone, fax, e-mail, entre outras informações não relacionadas à comunicação com o parlamentar. 
Está explicitado no site que a Casa não se responsabiliza pela comunicação estabelecida diretamente com o representante e há a sugestão de usar o canal "Fale Conosco" para que o cidadão esteja amparado pela Lei no 12.527/11 (conhecida como Lei de Acesso à Informação). Além deste canal, há diversas outras formas de interação com o parlamentar, disponíveis na seção "Participe", dentro de "Atividades Legislativas". Vale destacar que esse dispositivo legal rege apenas os pedidos de acesso à informação, e não as respostas às demandas da sociedade.

Após a coleta dos e-mails dos parlamentares, foram criadas quatro contas de correios eletrônicos de onde foram enviadas as mensagens. Cada endereço foi feito em nome de um membro do núcleo de pesquisa, liderado pelo orientador desta pesquisa e não foram dadas informações pessoais ou profissionais dos remetentes. Todo esse procedimento foi analisado e aprovado pelo Comitê de Ética da universidade.

Essas contas foram acessadas somente pela autora deste trabalho e seu orientador para manter sigilo absoluto sobre o conteúdo das comunicações. Não foi feita a divulgação das mensagens dos e-mails, a fim de não comprometer o contexto ético da pesquisa e garantir a integridade dos respondentes. É importante destacar que em nenhum momento o legislador - ou os membros da equipe que responde por ele - foi foco de análise, mas sim, a Câmara dos Deputados. Sendo assim, foram feitas as análises do conteúdo das respostas com o rigor metodológico e ético necessário para tanto.

Foram, então, enviados dois tipos de e-mails, que constituem os dois experimentos. No primeiro, os parlamentares receberam mensagens que continham (1) uma demanda de informação sobre um projeto em tramitação e o (2) posicionamento do político quanto a isso. Para delimitar os temas sobre os quais os legisladores foram questionados, foi feita uma consulta ao site da Câmara dos Deputados, nos meses de julho e agosto de 2017, em busca dos grandes projetos que seriam discutidos no ano corrente. Após a consulta, foram escolhidos quatro assuntos que ganharam visibilidade pela mídia: reforma da previdência, projeto "Escola Sem Partido", reforma política e refinanciamento de dívidas tributárias (Moraes, 2017; XAVIER, 2017; MIRANDA, 2017). No período de operacionalização da pesquisa foram verificados os projetos em andamento referentes a cada tema, tomando cuidado de perguntar apenas sobre os assuntos em tramitação na Casa Legislativa. 
Como a estrutura dos textos enviados era semelhante, para a melhor análise das respostas, optou-se por enviar dois e-mails sobre dois temas distintos para cada deputado, com intervalo de duas semanas entre eles. Para cada semana, os parlamentares foram divididos em dois grupos aleatoriamente, por meio de uma fórmula de sorteio de um editor de planilha.

O segundo experimento consistiu em enviar uma mensagem que continha um conteúdo mais simples e próximo ao que foi feito nas pesquisas anteriores. Por isso, foi enviada a mensagem que questionava a possibilidade de um contato com o parlamentar por aquele endereço eletrônico e se o político tentaria reeleição em 2018, inspirada nos trabalhos realizados na Espanha (DADER, 2003; DADER; DOMíngUEZ, 2011; DomíngUEZ, 2010) - por serem os pioneiros - e no Brasil (CUNHA; SANTOS, 2005) - para que se pudesse também comparar os índices de resposta do Legislativo local e federal. Vale destacar que os e-mails foram enviados de duas contas que já tinham sido usadas, mas para legisladores diferentes, ou seja, nenhum político recebeu mais de uma mensagem de cada remetente, o que poderia comprometer a pesquisa.

As mensagens foram enviadas automaticamente por meio de um editor de planilha sincronizada a um programa de e-mail. Essa planilha foi desenvolvida por um técnico especializado e pré-testes foram realizados, para verificar se as mensagens poderiam ser classificadas como spam por algum provedor. Além disso, após o envio, as contas foram checadas periodicamente para verificar se estavam recebendo e enviando mensagens.

\subsection{Análise de dados - Avaliação das respostas}

De posse das respostas, foi realizada uma avaliação do conteúdo dos textos, de forma objetiva e sistemática, para verificar a qualidade das mesmas. Foram, então, desmembradas as três dimensões adotadas por Grohs, Adam e Knill (2015) - velocidade, completude, orientação para o serviço - aqui tratadas como constructos a serem validados, e os critérios de avaliação foram construídos a partir deste estudo e com as instruções do Manual de Redação da Câmara dos Deputados e a Portaria no 96/2004 (que rege sobre o uso do correio eletrônico institucional da Câmara). 
Para a melhor compreensão dos constructos, foram trazidas definições para cada um deles. O verbete "velocidade" é definido como "relação entre espaço percorrido e tempo de percurso no movimento uniforme" (HoUAISS; VILLAR, 2001b, p. 2839). Nesta pesquisa, ele é percebido como o tempo que levou para que a resposta chegasse ao demandante. Assim sendo, este constructo foi medido apenas por uma proxy que trará o número de dias até receber o retorno, fazendo dele um constructo diferente dos demais.

"Completude" significa "qualidade, estado ou propriedade do que é completo, perfeito, acabado" (HouAISS; VILLAR, 2001a, p. 776). A compreensão desse constructo foi feita a partir das expectativas deste trabalho quanto ao "conteúdo completo" (fundamentadas pelos experimentos mencionados anteriormente), das orientações do Manual de Redação da Câmara dos Deputados (uma vez que eles trazem detalhes do que é um texto claro e preciso, conciso e harmônico) e da Portaria no 94 (2004, p. 163). Este documento estabelece as regras para o uso do correio eletrônico por todos que atuam na Câmara; dentre elas, há o artigo 15, parágrafo 2ํ, que diz que "Toda mensagem emitida por meio do serviço de correio eletrônico deverá conter a identificação clara de seu remetente, vedado o anonimato e qualquer forma de descaracterização da autoria".

A expressão "orientação para o serviço", por sua vez, foi aqui definida com base no artigo de Yuan, Yan e Liu (2009, p. 9, tradução nossa), que apresenta esse modelo de governo como sendo o que “almeja o objetivo de 'servir primeiro' e oferecer diversos serviços, dentre eles instituições, regras e ordens, que enfatizam alcançar a liberdade e os interesses dos cidadãos ao máximo, mas não o poder e a autoridade". Os autores concluem essa definição afirmando que "servir cidadãos é a fundamentação legal para a existência de um governo, e também a prioridade primeira do governo orientado para o serviço".

Para que a comunicação esteja dentro dos moldes da administração pública brasileira orientada para o serviço, entende-se que a mensagem precisa seguir, primeiramente, os princípios da formalidade, uniformidade e impessoalidade abordados no manual como essenciais para uma gestão democrática. Por fim, "abertura para contato posterior ou réplica" e "informações adicionais" são atributos marcantes de uma comunicação responsiva e aberta para o diálogo com o povo de forma geral (GROHS; AdAM; KNILL, 2015a). 
Vale destacar que os critérios para avaliar as variáveis que constituem este constructo também foram inspirados nas reflexões sobre funções do Poder Legislativo relacionadas à responsividade - que são a representativa, a comunicativa, a informativa e a educativa (MARQUES JÚNIOR, 2009; RIBEIRO, 2012). Essas responsabilidades que cabem ao Poder Legislativo fazem com que o contato de um cidadão não seja algo simples e direto, e sim um momento de levar conhecimento a esse indivíduo e fomentar sua cidadania. Diante disso, a expectativa desta pesquisa se direciona para um viés instrutivo dentro deste constructo.

Após o estudo dos temas, a leitura dos trabalhos anteriores e a realização do préteste, variáveis foram desenvolvidas, posteriormente desmembradas e descritas. Percebeuse, contudo, que esses critérios não conseguiram captar alguns detalhes importantes das respostas, tais como veracidade, originalidade, desleixo, descaso, discursos fechados para debate, entre outros. Partindo dessas observações, identificou-se a necessidade de se criar uma variável que permitisse uma avaliação dos pesquisadores quanto a esses pontos. Criou-se, para tanto, uma nova variável - denominada "satisfação percebida" que também faz parte do último constructo.

Para a melhor compreensão das variáveis e análise das respostas - e com base em tudo o que discutido até então -, foram criados critérios detalhados que estão dispostos na Figura 1. Como foram enviados dois tipos de mensagens, alguns critérios servem para ambos e outros apenas para um tipo. Por isso, os critérios destacados com a letra "a" foram utilizados para avaliar apenas as respostas dos e-mails com temas polêmicos; os demarcados com a letra "b", os retornos do e-mail simples; e os sem demarcações, servem para todas as respostas. 
Figura 1 | Variáveis e seus critérios de avaliação

\begin{tabular}{|c|c|c|}
\hline Variáveis & & Critérios \\
\hline $\begin{array}{l}\text { Tempo de resposta } \\
\text { (VT) }\end{array}$ & 1. & $\begin{array}{l}\text { Número de dias em que a resposta chegou, sendo que } 0 \text { se refere } \\
\text { àquela resposta recebida no mesmo dia (VT) }\end{array}$ \\
\hline \multirow{3}{*}{$\begin{array}{l}\text { Conteúdo } \\
\text { completo (CC) }\end{array}$} & 2. & Explicitar quem é o respondente (CC1) \\
\hline & 3. & Responder a primeira pergunta (CC2) \\
\hline & 4. & Responder a segunda pergunta (CC3) \\
\hline \multirow{3}{*}{$\begin{array}{l}\text { Clareza e precisão } \\
(\mathrm{CCP})\end{array}$} & 5. & $\begin{array}{l}\text { Usar palavras e expressões simples e de compreensão comum } \\
\text { (CCP1) }\end{array}$ \\
\hline & 6. & $\begin{array}{l}\text { Redigir frases objetivas e que estejam em ordem direta } \\
\text { (preferencialmente), sem intercalações e com pontuação adequada } \\
\text { (CCP2) }\end{array}$ \\
\hline & 7. & $\begin{array}{l}\text { O conteúdo deve estar de acordo com o que foi perguntado e não } \\
\text { pode gerar dúvida para o leitor (CCP3) }\end{array}$ \\
\hline \multirow{3}{*}{$\begin{array}{l}\text { Concisão e } \\
\text { harmonia }(\mathrm{CCH})\end{array}$} & 8. & $\begin{array}{l}\text { Escrever apenas o necessário, dispensando prolixidade, rodeios, } \\
\text { redundâncias, comentários supérfluos e caracterizações } \\
\text { inadequadas }(\mathrm{CCH} 1)\end{array}$ \\
\hline & 9. & $\begin{array}{l}\text { Colocar as ideias em sentenças curtas, de forma lógica e harmônica, } \\
\text { e sem repetições ( } \mathrm{CCH} 2)\end{array}$ \\
\hline & 10. & Observar concisão e coesão (CCH3) \\
\hline \multirow{3}{*}{ Formalidade (OF) } & 11. & Escrever com polidez, cortesia e respeito (OF1) \\
\hline & 12. & $\begin{array}{l}\text { Usar de linguagem apropriada, evitando uma abordagem } \\
\text { descontraída (OF2) }\end{array}$ \\
\hline & 13. & Usar a língua culta formal (OF3) \\
\hline \multirow{3}{*}{ Uniformidade (OU) } & 14. & Buscar coerência e constância no uso do tempo verbal (OU1) \\
\hline & 15. & $\begin{array}{l}\text { Seguir o estilo de linguagem e formato do documento estabelecidos } \\
\text { pelo manual de referência (OU2) }\end{array}$ \\
\hline & 16. & Respeitar as normas de ortografia (OU3) \\
\hline \multirow{3}{*}{$\begin{array}{l}\text { Impessoalidade } \\
\text { (OI) }\end{array}$} & 17. & $\begin{array}{l}\text { Respeitar a vontade estatal e buscar o bem comum nas ações feitas } \\
\text { em nome do serviço público, sem expressar distinção entre cidadãos } \\
\text { ou cometer algum tipo de ofensa (OI1) }\end{array}$ \\
\hline & 18. & $\begin{array}{l}\text { Não pedir que o cidadão se identifique ou faça algo semelhante para } \\
\text { então responder a (s) pergunta (s) (OI2) }\end{array}$ \\
\hline & 19. & $\begin{array}{l}\text { Não utilizar desse contato para fazer propaganda eleitoral ou pura } \\
\text { promoção de seu trabalho (OI3) }\end{array}$ \\
\hline
\end{tabular}




\begin{tabular}{|c|c|c|}
\hline Variáveis & & Critérios \\
\hline \multirow{3}{*}{$\begin{array}{l}\text { Abertura para } \\
\text { contato posterior } \\
\text { ou réplica (OAC) }\end{array}$} & 20. & $\begin{array}{l}\text { Disponibilizar outras formas de contato, que sejam institucionais ou } \\
\text { pessoais (OAC1) }\end{array}$ \\
\hline & 21. & $\begin{array}{l}\text { Deixar claro que o respondente está disposto a prestar mais } \\
\text { informações (OAC2) } \\
\text { Deixar claro que o respondente está disposto a manter um diálogo } \\
(\mathrm{OAC2})\end{array}$ \\
\hline & 22. & $\begin{array}{l}\text { Demonstrar interesse pela opinião do cidadão (OAC3) } \\
\text { Perguntar se o cidadão possui alguma dúvida, demanda ou sugestão } \\
\text { (OAC3) }\end{array}$ \\
\hline \multirow{3}{*}{$\begin{array}{l}\text { Informações } \\
\text { adicionais (OIA) }\end{array}$} & 23. & $\begin{array}{l}\text { Anexar material ou enviar o link para acessar o projeto em si e/ou } \\
\text { seu andamento } \\
\text { Explicar que o contato com o parlamentar é aberto a todos (OIA1) }\end{array}$ \\
\hline & 24. & $\begin{array}{l}\text { Trazer embasamento e/ou justificativa para a opinião quanto ao } \\
\text { tema (OIA2) } \\
\text { Deixar explícito como ocorre a comunicação com o parlamentar (se } \\
\text { passa pelo gabinete, se há filtragem, etc.) (OIA2) }\end{array}$ \\
\hline & 25. & $\begin{array}{l}\text { Mencionar outros projetos, propostas similares e/ou outras } \\
\text { informações pertinentes (OIA3) } \\
\text { Instruir acerca do processo de escolha dos candidatos pelos partidos } \\
\text { (OIA3) }\end{array}$ \\
\hline \multirow{3}{*}{$\begin{array}{l}\text { Satisfação } \\
\text { Percebida (OSP) }\end{array}$} & 26. & $\begin{array}{l}\text { Informar corretamente o cidadão e mencionar a fonte de trechos } \\
\text { provenientes de textos escritos por outrem (OSP1) } \\
\text { Demonstrar abertura e deixar o eleitor à vontade para contatá-lo } \\
\text { novamente (OSP1) }\end{array}$ \\
\hline & 27. & $\begin{array}{l}\text { Responder com o afinco, sem transparecer desleixo e/ou descaso } \\
\text { (OSP2) }\end{array}$ \\
\hline & 28. & $\begin{array}{l}\text { Demonstrar abertura para o debate do tema na Casa e apresentar } \\
\text { uma atitude receptiva aos argumentos postos, mesmo que de } \\
\text { posicionamento contrário (OSP3) } \\
\text { Mencionar a questão da regionalidade da representação, sem excluir } \\
\text { os cidadãos dos demais estados (OSP3) }\end{array}$ \\
\hline
\end{tabular}

Fonte: elaboração própria (2018).

Com esse embasamento, avaliou-se e mensurou-se o que foi captado em cada critério através de uma escala métrica de classificações somadas, seguindo as instruções de Hair et al. (2005), que se constitui em um instrumento de mensuração que utilizou de sete pontos para captar a qualidade da resposta dentro de cada categoria. De acordo com a avaliação feita, as respostas foram alocadas na escala que possui uma pontuação variando de um a sete correspondendo às seguintes classificações: péssimo, muito ruim, ruim, regular, bom, muito bom e excelente, e ao final foi somada para se ter uma nota por categoria. A nota 
"zero" é atribuída, por exemplo, quando uma das perguntas não foi respondida, ou seja, quando não há nada escrito na resposta que possa ser atribuído àquele critério.

Para a proxy de velocidade, foi feita uma escala numérica cuja pontuação regrediu de acordo com o tempo de resposta. O prazo máximo de recebimento estabelecido foi de 21 dias, tempo escolhido em cumprimento à Lei de Acesso à Informação (Lei 12.527/11) - que delimita vinte dias como sendo o período de resposta de órgãos públicos - e adaptado para se adequar à escala aqui proposta. Sendo assim, as faixas da régua foram diferenciadas pelo intervalo de três dias - 3, 6, 9, 12, 15, 18, 21 - e a pontuação foi a mesma atribuída anteriormente, sendo feita, contudo, em ordem inversa, uma vez que a resposta mais rápida ganhou a maior pontuação.

Por fim, quatro outros pontos foram observados: se houve resposta para a primeira pergunta (RA), se houve resposta para a segunda pergunta (RP), se foi o próprio deputado que respondeu (DR) e sua manifestação sobre a matéria (OM - experimento 1) ou sobre a tentativa de reeleição (TR - experimento 2 ).

\subsection{Análise de dados - Tratamento estatístico dos resultados}

De posse dessas avaliações, foram feitas médias simples dos vinte e oito critérios de avaliação dispostos na Figura 1, dando origem a uma variável denominada "Média Final" (MF). Vale reiterar que os parlamentares em si não são foco deste estudo, portanto, foram analisadas as respostas recebidas.

Após quantificar os resultados, utilizou-se o software de tratamento de dados Statistical Package for the Social Sciences v. $20.0^{\circledR}$ (SPSS) para a realização de uma Análise Exploratória de Dados (AED), que consiste na análise e descrição das informações coletadas, que permite a extração de relações e frequências para melhor conhecimento dos mesmos antes da aplicação de uma técnica estatística (HAIR, 2009).

Feito isso, foram realizados testes de hipóteses com dois intuitos: (1) observar se há diferença das médias (variável dependente) em relação às variáveis qualitativas e (2) verificar se houve diferença nos resultados dos dois experimentos. 
Os primeiros cruzamentos partiram da variável dependente MF, de caráter métrico (também chamada de quantitativa) com as variáveis categóricas que representam os outros quesitos; algumas contam com duas e umas com quatro categorias. Os testes aplicados neste momento foram: "t de student" para os primeiros e "Anova" para o último quesito, ambos considerando que as amostras são independentes, segundo as instruções de Hair (2009).

A segunda parte dos cruzamentos comparou as médias, as mínimas e as máximas obtidas na avaliação de cada variável, em cada experimento. Para tanto, foi realizado o teste não-paramétrico de Wilcoxon para amostras emparelhadas. Optou-se por um teste não-paramétrico por conta do baixo número de casos e de variáveis observadas, como instruem Pestana e Gageiro (2008).

\section{Resultados e discussões}

Dos primeiros 1.026 e-mails enviados, apenas sete não chegaram aos destinatários, e isso ocorreu apenas na segunda seção de envio. As mensagens de falha de entrega de cinco deles continham a seguinte mensagem: "O endereço de $e$-mail que você inseriu não pôde ser encontrado". O perfil de quatro destes no site da câmara continha a seguinte mensagem: "*** não está em exercício ***”. Foram identificados os suplentes de três deles e as mensagens foram encaminhadas. Não foi possível detectar o problema da quinta conta.

Quanto às duas restantes, recebeu-se a seguinte notificação: "A caixa de correio do destinatário está cheia e não pode aceitar mensagens no momento". Devido a esses fatos, 1.022 e-mails no total - 99,61\% - foram enviados com sucesso. Sobre isso, consta no Manual do Gabinete Parlamentar (2014) que é de responsabilidade do usuário da conta a limpeza periódica da caixa postal.

Apenas uma resposta automática foi recebida - geralmente usada para acusar recebimento enquanto o respondente prepara a resposta - também na segunda semana. Vale destacar que não houve retorno oficial desse remetente e, portanto, essa resposta não foi contabilizada. 
Na terceira semana, os mesmos erros de envio ocorreram, sendo que dois parlamentares possuíam suas caixas de entrada cheias e um endereço eletrônico não foi encontrado (não foi possível constatar a razão do erro do último), totalizando 510 e-mails enviados com sucesso - 99,02\%. Foram analisadas as respostas recebidas até o dia 5 de novembro.

Primeiramente, observou-se o baixíssimo retorno no primeiro experimento (27 respostas, o que equivale a $2,64 \%$ ). Esse percentual foi o menor se comparado a todos os estudos anteriores, até mesmo os que datam de um momento de adaptação da administração pública à internet. Ao comparar especificamente com os resultados de Cunha e Santos (2005), observou-se o maior número de respostas por parte do Poder Legislativo local, o que contraria a expectativa deste estudo, por partir da perspectiva de que as instâncias federais possuem mais recursos para atender os cidadãos, logo, teriam mais condições - tanto no sentido financeiro quanto de pessoal disponível e preparado para responder.

Em seguida, percebe-se uma considerável discrepância no número de respostas do segundo experimento. Apenas no primeiro dia, 89 respostas foram recebidas, quatro vezes o quantitativo total do primeiro experimento. Ao final, foram recebidas 125 respostas (24,37\%). Infere-se, a partir disso, que os parlamentares preferem não se posicionar quando os assuntos são polêmicos.

Apesar de o segundo experimento ter tido maior número de respostas, esse resultado foi melhor apenas que os obtidos por Dader e Dominguez (2011) e Cunha e Santos (2005), que consistem nos trabalhos mais antigos dentre os estudos coletados e dos quais este artigo se baseou para formular a mensagem do experimento. A partir disso, pode-se entender que o ato de retornar um e-mail - neste caso - não depende de questões financeiras ou tecnológicas, mas sim, da motivação do agente.

Vale pontuar que apenas um legislador respondeu a todos os e-mails e que quatorze responderam a uma mensagem do primeiro experimento e ao segundo também. Esperavase que todos os respondentes do primeiro experimento também retornassem ao segundo, uma vez que o tema era mais simples e de interesse direto dos parlamentares. Quanto à questão da qualidade das respostas, estas foram analisadas nos subtópicos que seguem. 


\subsection{Análises das respostas do primeiro experimento}

Este experimento constituiu em enviar e-mails para os deputados perguntando sobre o andamento de uma proposta de projeto de lei considerada polêmica, além do seu posicionamento quanto a ela.

Primeiramente, as notas atribuídas a cada variável passaram por uma análise estatística descritiva, em que se observou a nota mínima, a máxima, a média e o desvio padrão das variáveis quantitativas do estudo. A Tabela 1 expõe esses resultados e as discussões estão a seguir:

Tabela 1 | Análise descritiva do primeiro experimento

\begin{tabular}{|c|c|c|c|c|c|c|c|c|c|c|c|}
\hline & Mínimo & Máximo & Média & & Mínimo & Máximo & Média & & Mínimo & Máximo & Média \\
\hline VT & 1 & 7 & 5,52 & $\mathrm{CCH} 3$ & 0 & 7 & 5,96 & OI3 & 0 & 7 & 6,44 \\
\hline CC1 & 2 & 7 & 6,56 & OF1 & 2 & 7 & 6,22 & OAC1 & 0 & 7 & 2,78 \\
\hline $\mathrm{CC} 2$ & 0 & 7 & 3,41 & OF2 & 2 & 7 & 5,63 & OAC2 & 0 & 7 & 1,48 \\
\hline $\mathrm{CC} 3$ & 0 & 7 & 3,48 & OF3 & 3 & 7 & 5,93 & OAC3 & 0 & 0 & 0,00 \\
\hline CCP1 & 4 & 7 & 6,59 & OU1 & 3 & 7 & 6,30 & OIA1 & 0 & 7 & 1,67 \\
\hline CCP2 & 2 & 7 & 4,93 & OU2 & 1 & 7 & 4,37 & OIA2 & 0 & 7 & 2,26 \\
\hline CCP3 & 0 & 7 & 4,44 & OU3 & 1 & 7 & 6,67 & OIA3 & 0 & 7 & 1,89 \\
\hline $\mathrm{CCH} 1$ & 3 & 7 & 5,26 & Ol1 & 0 & 7 & 3,30 & OSP1 & 0 & 7 & 3,41 \\
\hline \multirow[t]{2}{*}{$\mathrm{CCH} 2$} & 4 & 7 & 6,22 & $\mathrm{O} 12$ & 2 & 7 & 6,81 & OSP2 & 0 & 7 & 4,07 \\
\hline & & & & & & & & OSP3 & 0 & 7 & 2,41 \\
\hline
\end{tabular}

Fonte: elaboração própria. (2018).

Observa-se que o fator OAC3 - intitulado "Demonstrar interesse pela opinião do cidadão" - não foi considerado por nenhum respondente, resultado alarmante no quesito democrático do contato estabelecido. Comparando as notas mínimas e máximas atribuídas a alguns critérios, verificam-se diversas discrepâncias nas respostas. Isso se confirma ao verificar que, das 28 variáveis, quinze apresentam seu desvio padrão equivalente a mais de um terço da média, o que indica que as notas variam muito nessas variáveis (VT, CC2, CC3, CCP2, CCP3, OU2, OI1, OI2, OAC1, OAC2, OIA1, OIA2, OIA3, OSP1, OSP2, OSP3). 
Desses critérios que variaram significativamente, onze obtiveram médias inferiores a 4, ou seja, foram qualificadas como ruim, muito ruim, péssimo ou o critério não identificado. Dentre essas variáveis estão as que verificam se foi respondida a primeira pergunta (CC2) e a segunda (CC3) pergunta, em outras palavras, alguns respondentes retornaram, mas responderam apenas uma ou nenhuma pergunta feita.

Outro quesito é que as notas são atribuídas de acordo com o tempo que levou para chegar a mensagem, com o respeito às regras de redação ditadas pela Câmara, com o conteúdo e com o dever de manter um contato democrático. O segundo fator mencionado foi responsável por fazer com que $59,26 \%$ das respostas fossem avaliadas de regulares para cima, mesmo que o conteúdo e o cunho democrático não fossem respeitados.

Destaca-se, também, o fato de que em todos os critérios - exceto o OAC3 - pelo menos um respondente que conquistou nota máxima e que o zero não foi nota mínima para todos, o que leva a uma percepção promissora dos resultados. Ainda sobre isso, observouse que os critérios "usar palavras e expressões simples e de compreensão comum" e "colocaras ideias em sentenças curtas, de forma lógica e harmônica, e sem repetições", obtiveram as menores mínimas, reforçando a compreensão de que as questões de escrita são mais respeitadas nas mensagens recebidas.

Dentre as variáveis qualitativas, destacou-se a "opinião manifesta", uma vez que nenhum dos legisladores se posicionou a favor de nenhum dos projetos (ver Tabela 4), ou seja, aqueles que responderam eram contra a proposta ou não possuíam posicionamento. Não se pode inferir que os legisladores preferem não se manifestar quando se trata de apoiar questões polêmicas porque o percentual de respostas não representa os deputados, mas esse foi um resultado interessante de se pontuar.

Verificou-se também que grande parte das respostas foram enviadas por assessores dos parlamentares (11 das 27), o que já se esperava por conta dos diversos compromissos que os legisladores federais têm, além de contarem com verba destinada à contratação de pessoal que pode ser designado à gerência de correspondência.

Ainda sobre as qualitativas, foram feitos testes para verificar se as médias variam de acordo com os quesitos. Para as variáveis com duas categorias foi aplicado o teste " $t$ de student", enquanto o Anova foi aplicado para o "opinião manifesta". Os dois primeiros 
critérios mostraram diferenças estatísticas em suas médias, indicando que quando as perguntas são respondidas, a nota é de fato mais alta.

Verificou-se também as saídas referentes às médias das respostas (vide Tabela 2), possibilitando observar uma baixa variação das notas ao considerar que o desvio padrão corresponde a menos de $20 \%$ da média, ou seja, a distribuição das notas está concentrada na categoria "regular".

Tabela 2 | Análise da variável Média Final

\begin{tabular}{cccccc}
\hline Estatísticas & N & Mínimo & Máximo & Média & $\begin{array}{c}\text { Desvio } \\
\text { Padrão }\end{array}$ \\
\hline Resultados & 27 & 2,857 & 6,071 & 4,428 & 0,8544 \\
\hline Categoria & Muito ruim & Ruim & Regular & Bom & Muito bom \\
\hline № de médias & 1 & 8 & 11 & 6 & 1 \\
\hline
\end{tabular}

Fonte: resultados da pesquisa, elaboração própria. (2018).

Por fim, foram dispostas na escala de mensuração quantas médias finais se encaixaram em cada categoria de pontuação, como pode se observar na Tabela 6 . Identifica-se que os resultados se concentraram entre os conceitos "ruim" e "bom", com maior concentração no "regular" (que coincidiu com a média da Tabela 4), indicando que a qualidade das respostas a questões polêmicas precisa melhorar consideravelmente para poder ser chamada de responsiva.

\subsection{Análises das respostas do segundo experimento}

Este segundo experimento, por sua vez, foi enviar e-mails perguntando se um cidadão comum poderia se comunicar com o parlamentar por aquele endereço eletrônico e se o deputado iria tentar a reeleição.

Assim como feito na seção anterior, deu-se início às discussões a partir da análise exploratória dos dados, como disposto na Tabela 3 (seguida pelas respectivas reflexões), que expõe esses resultados e os discute a seguir: 
Tabela 3 | Análise descritiva do segundo experimento

\begin{tabular}{|c|c|c|c|c|c|c|c|c|c|c|c|}
\hline & Mínimo & Máximo & Média & & Mínimo & Máximo & Média & & Mínimo & Máximo & Média \\
\hline VT & 1 & 7 & 6,61 & $\mathrm{CCH} 3$ & 0 & 7 & 4,98 & OAC1 & 0 & 7 & 2,29 \\
\hline $\mathrm{CC} 1$ & 0 & 7 & 5,75 & OF1 & 1 & 7 & 6,62 & OAC2 & 0 & 7 & 4,78 \\
\hline CC2 & 0 & 7 & 4,87 & OF2 & 1 & 7 & 5,22 & OAC3 & 0 & 7 & 0,51 \\
\hline $\mathrm{CC} 3$ & 0 & 7 & 3,73 & OF3 & 1 & 7 & 5,50 & OIA1 & 0 & 7 & 1,53 \\
\hline CCP1 & 4 & 7 & 6,89 & OU1 & 5 & 7 & 6,97 & OIA2 & 0 & 7 & 4,48 \\
\hline CCP2 & 0 & 7 & 4,55 & OU2 & 1 & 7 & 4,22 & OIA3 & 0 & 7 & 0,36 \\
\hline ССР 3 & 0 & 7 & 4,72 & OU3 & 0 & 7 & 6,36 & OSP1 & 0 & 7 & 4,75 \\
\hline $\mathrm{CCH} 1$ & 1 & 7 & 5,66 & OI1 & 0 & 7 & 4,68 & OSP2 & 0 & 7 & 4,47 \\
\hline \multirow[t]{2}{*}{$\mathrm{CCH} 2$} & 1 & 7 & 5,86 & OI2 & 0 & 7 & 6,26 & OSP3 & 0 & 7 & 0,44 \\
\hline & & & & Ol3 & 1 & 7 & 6,06 & & & & \\
\hline
\end{tabular}

Fonte: elaboração própria. (2018)

O OAC3 - que teve o pior resultado no experimento anterior e consiste em “perguntar se o cidadão possui alguma dúvida, demanda ou sugestão" neste - apareceu em algumas respostas, ainda que em poucas e de forma não muito clara (vê-se que sua média é "péssima" - 0,51). Neste experimento, nenhum foi ignorado por completo; contudo, outros dois tiveram médias ainda menores que o OAC3: "instruir acerca do processo de escolha dos candidatos pelos partidos" (OIA3) e "mencionar a questão da regionalidade da representação, sem excluir os cidadãos dos demais estados" (OSP3). Ambos estão relacionados diretamente às funções educativa e informativa do Poder Legislativo e deveriam estar explícitos para que o cidadão não interpretasse erroneamente como funciona o processo de escolha dos candidatos e a questão de representar o estado de origem, sem ignorar o bem coletivo de forma geral.

Passando para as discrepâncias entre as notas mínimas e máximas, identificamse mais variáveis que no outro experimento - dezessete - revelando que a qualidade das respostas em geral variou mais (CC1, CC2, CC3, CCP2, CCP3, CCH3, OF2, OU2, OAC1, OAC2, OAC3, OIA1, OIA2, OIA3, OSP1, OSP2, OSP3). É importante enfatizar também que o número de notas mínimas zero - que era quinze no experimento anterior - é dezoito entre as respostas desta investigação, revelando respostas inadequadas em mais fatores. 
Repete-se neste experimento a questão de os critérios ligados à escrita serem responsáveis por "subir" as notas de mensagens ruins. Pode-se verificar isso a partir das notas mínimas 5 - buscar coerência e constância no uso do tempo verbal (OU1) - e 4 usar palavras e expressões simples e de compreensão comum (CCP1) - conquistadas em quesitos relacionados à forma de escrever.

Outra vez, todos os critérios tiveram notas 7 como máximas. Em geral, as médias das variáveis do segundo experimento foram altas. Verificou-se que $77,77 \%$ das variáveis receberam notas de regulares para cima, mesmo que o conteúdo e o cunho democrático não fossem respeitados.

Passando para as variáveis nominais, mais uma vez a relacionada à manifestação do legislador quanto à segunda pergunta chamou atenção. Apenas um respondente não tentará reeleição e a maioria não comentou sobre essa questão (68 dos 125). Por conta da oportunidade de fazer contato com um eleitor interessado, havia a expectativa de que as manifestações predominantes fossem de reeleição - ou intenção de tentar outro cargo - e indecisos - por conta das agendas dos partidos.

Os testes realizados no primeiro experimento foram também aplicados no segundo, exceto o Anova, que teve que ser substituído pela sua versão não-paramétrica "Kruskal-Wallis", pois umas das categorias da variável tinha menos de dois casos ("Não"). Novamente, os dois primeiros critérios apresentam médias diferentes para cada grupo, e o terceiro, não. A quarta variável, diferente do primeiro experimento, também apresentou um sig que aponta para diferença estatística na distribuição em pelo menos um dos grupos em relação aos outros.

Passando para a análise descritiva das médias finais das respostas (vide Tabela 4), identificou-se que o desvio corresponde à cerca de $17 \%$ da média, indicando uma baixa variação nas notas das respostas e uma concentração na categoria "regular", assim como no primeiro experimento. 
Tabela 4 | Análise da variável Média Final

\begin{tabular}{lccccc}
\hline Estatísticas & N & Mínimo & Máximo & Média & $\begin{array}{c}\text { Desvio } \\
\text { Padrão }\end{array}$ \\
\hline Resultados & 125 & 2,142 & 6,214 & 4,611 & 0,801 \\
\hline Categoria & Muito ruim & Ruim & Regular & Bom & Muito bom \\
\hline N. de médias & 5 & 20 & 56 & 42 & 2 \\
\hline
\end{tabular}

Fonte: resultados da pesquisa, elaboração própria. (2018)

A análise do segundo experimento também foi finalizada com a tabela que separa as notas por categoria. Desta vez, houve maior concentração de notas em "regular" e "bom" - mantendo o destaque no primeiro - reiterando a interpretação do tópico anterior, mostrando que e-mails com conteúdo mais simples possuem uma tendência maior a serem respondidos responsivamente, apesar de as notas continuarem sendo baixas.

Para a melhor compreensão das diferenças entre os resultados dos dois experimentos, foram abordadas comparações entre eles na seção 4.3.

\subsection{Comparações entre os experimentos}

Para verificar se houve de fato diferença entre as respostas dos experimentos, foram realizados testes de Wilcoxon para amostras emparelhadas, verificando o mínimo, o máximo e as médias de cada critério e da média final. De forma geral, os resultados do primeiro experimento foram melhores. Contudo, estatisticamente, apenas as notas mínimas variaram de fato, tendo o experimento 1 uma média geral superior. Isso pode ser atrelado ao fato de que perguntas complexas exigem respostas mais bem trabalhadas (quando respondidas, neste caso), sendo a elas atribuídas menos notas baixas nos critérios.

Notou-se, também, que em ambos houve falta de padrão nos textos e nas assinaturas (até mesmo falta de identificação, algo regulado pela portaria que rege o uso de correio eletrônico), carência de cuidado na leitura do que foi perguntado (uma vez que em diversos casos algumas das perguntas foi ignorada) e - um pouco menos frequente, mas marcante - desleixo na redação. Compreende-se, assim, que por mais que haja um manual para instruir sobre o uso do correio eletrônico e o modo de redigir as mensagens, essas informações são ignoradas. 
Em termos de uma interação democrática, esta não ocorreu de fato, pois não foi dado ao cidadão o tratamento devido em termos de: resposta ao seu contato, prestação de informações sobre seus direitos, demonstração de interesse pela sua opinião e instrução sobre questões políticas.

Os resultados encontrados neste experimento divergem do cenário de uma democracia representativa que atua responsivamente perante os cidadãos, como apresentado por Pitkin (1967), tanto por não ter havido um número de respostas condizentes com o investimento em tecnologia e com as normas que regem esse tipo de contato, quanto pela qualidade das respostas, que deixou a desejar, mas, sobretudo, pela razão de ser de um mandato parlamentar, qual seja, o de ser o representante do cidadão.

\section{Considerações finais}

Este trabalho buscou investigar o grau de responsividade dos deputados federais brasileiros quando contatados por um cidadão por um meio eletrônico. Destaca-se que esta foi a primeira pesquisa a indagar parlamentares sobre seu posicionamento acerca de temas polêmicos e que usou de critérios complexos para analisar as respostas.

Comparado aos estudos anteriores aqui levantados, o quantitativo de retorno foi irrisório no experimento (cujas mensagens envolviam as questões polêmicas), e o segundo (que indagava sobre questões simples) teve resultados maiores apenas que dois estudos, que datam de cerca de dez anos atrás. Antes de se realizar essas investigações, foi constatado que não havia impedimentos para que os legisladores respondessem em termos de recursos tecnológicos e humanos; ainda assim, o índice de retorno foi baixíssimo. Cunha e Santos (2005) obtiveram resultados semelhantes e concluíram que os políticos possuem os instrumentos para se comunicarem com os cidadãos; entretanto, quando contatados, não retornam. Essa foi a mesma interpretação - doze anos depois obtida nesta pesquisa.

Analisando o índice de retorno dos dois experimentos, pode-se inferir que os parlamentares preferem não se manifestar quando os assuntos são polêmicos. $O$ fato de nenhum deputado se posicionar a favor dos projetos no primeiro experimento reforça 
essa inferência. Essa é uma questão dicotômica, pois a votação em plenário é aberta, o que levaria à expectativa de que os parlamentares se manifestassem. Esse fato converge - considerando as devidas proporções - com o experimento de West (2004), confirmando a inferência quanto à omissão dos deputados.

No quesito qualidade das respostas, foi possível inferir que os maiores problemas não são técnicos, ou gramaticais, mas sim de cunho democrático, no sentido de que não foram dadas as devidas instruções e tampouco foi construído um diálogo com o cidadão.

Entende-se, com tudo isso, que o investimento feito pela Câmara dos Deputados em comunicação direta entre parlamentar e cidadão não tem relação com o grau de responsividade dos legisladores quando contatados por um meio que não sofre fiscalização, e que o ato de responder (ou não) e como responder depende da vontade individual dos mesmos e/ou de seus assessores. Nesse quesito, então, quanto ao uso de e-mails, os parlamentares não estão sendo responsivos, ferindo a efetividade do regime democrático representativo.

Por fim, destaca-se que este experimento propôs um protocolo de coleta e análise de dados que pode ser replicado em estudos futuros - como é feito em outros países - sem restrição de poder, instituição ou ente a ser aplicado. Como também foi feito no exterior, sugere-se a replicação deste experimento nos governos subnacionais, para verificar se o poder local é mais próximo do cidadão também sob o viés da responsividade. Além disso, este tipo de experimento pode ser feito utilizando outras mídias, tais como site oficial, Facebook, Twitter, Instagram, entre outros.

\section{Referências bibliográficas}

ANDERSEN, K. N. et al. The forgotten promise of e-government maturity: assessing responsiveness in the digital public sector. Government Information Quarterly, v. 28, n. 4, p. 439-445, 2011.

BeEtham, D. (Ed.). Parliament and democracy in the twenty-first century: a guide to good practice. Switzerland: Inter-Parliamentary Union, 2006.

BRAGA, S.; Nicolas, M. The parliament and the Internet: sociopolitical profile and use of the internet by the parliamentary elites of Argentina, Brazil, Paraguay, Uruguay, Venezuela and 
Chile. In: XXI IPSA World Congress of Political Science. Santiago: 2009. Disponível em: <http:// paperroom.ipsa.org/app/webroot/papers/paper_2297.pdf>. Acesso em: 8 fev. 2017

BRAgA, S. S.; Mitozo, I. B.; TADRA, J. As funções desempenhadas pelos websites parlamentares brasileiros e o papel dos programas educativos. Educação \& Sociedade, v. 37, n. 136, p. 793-819, 2016.

Brasil. Congresso nacional. Câmara dos Deputados. Código de ética e decoro parlamentar. 4. ed. Brasília: Câmara dos Deputados, Edições Câmara, 2015.

CÂMARA dos Deputados. Portaria n 96, de 2004. 2004.

Castro, C. L. F. De; Gontijo, C. R. B.; Amabile, A. E. De N. (Eds.). Dicionário de Políticas Públicas. Barbacena: EdUEMG, 2012.

CLEARY, M. R. The sources of democratic responsiveness in Mexico. Notre Dame, Ind: University of Notre Dame Press, 2010.

CRUZ, L. C. Elites parlamentares e NTICS: um estudo sobre o uso da internet pelos deputados estaduais brasileiros da 16 legislatura (2007-2011). Dissertação (Mestrado em Ciência Política) Curitiba: Universidade Federal do Paraná, 2011.

CUNHA, M. A. V. C.; SANTOS, G. S. O uso de meios eletrônicos no relacionamento do parlamentar com o cidadão nos municípios brasileiros. Organizações \& Sociedade, v. 12, n. 35, p. 69-89, 2005.

DADER, J. L. Ciberdemocracia y ciberparlamento. El uso de correo elctrónico entre los parlamentarios españoles y ciudadanos comunes (1999-2001). Telos: Cuadernos de Comunicación, Tecnología y Sociedad, n. 55, p. 86-96, 2003.

DADER, J. L.; DomíngUEZ, E. M. C. Internet parlamentario en España (1999-2005): los recursos para el contacto ciudadano y su uso, con una comparación europea. Zer-Revista de Estudios de Comunicación, v. 11, n. 20, 2011.

Denhardt, R. B. Teorias da Administração Pública. São Paulo: Cengage Learning, 2015.

Departamento de Apoio Parlamentar. Manual do Gabinete Parlamentar. Brasília: Câmara dos Deputados, 2014.

DomínGUEZ, E. M. C. La comunicación directa entre los diputados del Congreso y los ciudadanos a través del correo electrónico: nuevos hábitos de información y participación ciudadana en la VIII legislatura de las cortes. Doxa Comunicación. Revista Interdisciplinar de Estudios de Comunicación y Ciencias Sociales, n. 11, p. 55-75, 2010.

FEREJOHN, J. Accountability and Authority: toward a theory of political accountability. In:

PrZEWORSKI. A; StOKes, S. C.; MANIN, B. (Eds.). Democracy, Accountability, and Representation, Cambridge Studies in the Theory of Democracy. Cambridge: Cambridge University Press, 1999. pp. 131-153.

FONSECA, J. J. S. Metodologia da pesquisa científica. Fortaleza: UEC, 2002. 
GAULD, R. et al. How responsive are government agencies when contacted by email? Findings from a longitudinal study in Australia and New Zealand. Government Information Quarterly, v. 33, n. 2, p. 283-290, 2016.

Gerhardt, T. E.; Silveira, D. T. (Eds.). Métodos de Pesquisa. Porto Alegre: Editora da UFRGS, 2009.

Grohs, S.; AdAM, C.; KNILL, C. Are Some Citizens More Equal than Others? Evidence from a Field Experiment. Public Administration Review, v. 76, n. 1, p. 155-164, 2015.

Grohs, S.; AdAM, C.; KNILL, C. Are Some Citizens More Equal than Others? Evidence from a Field Experiment. Public Administration Review, v. 76, n. 1, p. 155-164, 2015b.

HAIR, J. F. et al. Fundamentos de métodos de pesquisa em administração. Porto Alegre: Bookman, 2005.

HAIR, J. F. Análise multivariada de dados. Porto Alegre: Bookman, 2009.

Houalss, A.; VILLAR, M. S. Completude. Dicionário Houaiss da Língua Portuguesa. Rio de Janeiro: Objetiva, 2001a.

Houalss, A.; VILLAR, M. S. Velocidade. Dicionário Houaiss da Língua Portuguesa. Rio de Janeiro: Objetiva, 2001b.

MARQUES JÚNIOR, A. M. Educação legislativa: as escolas do Legislativo e a função educativa do parlamento. E-legis, v. 2, n. 3, p. 73-86, 2009.

MIRANDA, T. Ano legislativo de 2017 será marcado por inúmeras propostas polêmicas. Disponível em: <http://www2.camara.leg.br/>. Acesso em: 10 mar. 2017.

Moraes, G. Comissão aprova texto da reforma política; "distritão" pode ser incluído nos destaques. Disponível em: <http://www2.camara.leg.br/>. Acesso em: 10 ago. 2017.

MOREIRA, T. C. F. Qualidade da democracia, representação e congruência política: um debate teórico-normativo e empírico. In: 9o Congreso Latinoamericano de Ciencia Política, organizado por la Asociación Latinoamericana de Ciencia Política (ALACIP). Montevideo: 2017. Disponível em: <http://www.congresoalacip2017.org/arquivo/ iO30iO3M6MToiaCl7czozMjoiYjg0MGIwZTQzMTIzMmlyYjliNzRiODE3MGE0MTk2ZDMiO30\%3Df>. Acesso em: 13 mar. 2020.

Nicolás, M. A.; OLIVEIRA, R. C. Internet, parlamentares e contexto off-line: websites parlamentares em contextos institucionais diferentes. Curitiba: Tese (Doutorado em Sociologia) -Universidade Federal do Paraná, 2015.

Окот-UMA, R. W.; LONDON, C. S. Electronic governance: re-inventing good governance. London: Commonwealth Secretariat, 2000.

Pestana, M. H.; Gageiro, J. N. Análise de dados para ciências sociais: a complementariedade do SPSS. 5a ed. Lisboa: Silabo, 2008.

PITKIN, Hanna F. The concept of representation. Univ of California Press, 1967. 
RibeIRo, G. W. Funcionamento do poder legislativo municipal. Brasília: Senado Federal, Secretaria Especial de Editoração e Publicações. v. 5, 2012.

RICKEN, F. A. G.; BRAGA, S. S. Entre a mobilização e a informação: uso da internet pelos parlamentares no Brasil e nos EUA. In: IV Congresso Latino Americano de Opinião Pública da Wapor. Belo Horizonte: 2011.

VIGodA, E. Are You Being Served? The Responsiveness of Public Administration to Citizens' Demands: An Empirical Examination in Israel. Public Administration, v. 78, n. 1, p. 165-191, 2000.

VIGODA, E. From Responsiveness to Collaboration: Governance, Citizens, and the Next Generation of Public Administration. Public Administration Review, v. 62, n. 5, p. 527-540, 2002.

WEST, D. M. State and federal e-government in the United States. Providence: Brown University, 2003. Disponível em: <https://www.brown.edu/academics/taubman-center/sites/brown.edu. academics.taubman-center/files/uploads/egovt03us(1).pdf>. Acesso em: 2 mar. 2017.

XAVIER, L. G. Congresso e governo buscam acordo sobre MP que refinancia dívidas tributárias. Disponível em: <http://www2.camara.leg.br/>. Acesso em: 10 ago. 2017.

YUAN, G.; YAN, S.T.; LIU, Q. A study on the rising of service-oriented government. Journal of USChina Public Administration, v. 6, n. 7, p. 8-16, 2009.

\section{Luíza Amália Soares Franklin}

(D) http://orcid.org/0000-0001-5385-7161

Doutoranda em Administração Universidade Federal de Viçosa (UFV). Bacharel em Secretariado Executivo Trilíngue e Mestre em Administração pela UFV.

E-mail: luizafranklin.ufv@gmail.com

\section{Marco Aurélio Ferreira Marques}

(D) http://orcid.org/0000-0002-9538-1699

Pós-Doutor em Administração Pública pela Rutgers University (Nova Jersey - EUA). Bacharel em Administração e Doutor em Economia Aplicada pela Universidade Federal de Viçosa-UFV. Professor Associado da Universidade Federal de Viçosa, atuando no ensino, pesquisa e extensão nos cursos de graduação em Administração e Contabilidade e nos Programas de Pós-graduação em Administração e de Extensão Rural como orientador no Mestrado e Doutorado. Bolsista de Produtividade do CNPq em Administração Pública.

E-mail: marcoufv1@gmail.com

\section{Ana Paula Teixeira Campos}

(iD) http://orcid.org/0000-0002-3527-2730

Doutora em Ciências Sociais em Desenvolvimento, Agricultura e Sociedade, pela Universidade Federal Rural do Rio de Janeiro (CPDA/UFRRJ). Mestre em Extensão Rural (2016) e Pós-doutorado em Administração (2018) com ênfase em Administração Pública na Universidade Federal de Viçosa (UFV). Bolsista de extensão pelo CNPq em projeto vinculado ao Instituto de Políticas Públicas e Desenvolvimento Sustentável (IPPDs/UFV).

E-mail: ana.p.campos@ufv.br 